\section{DISCURSOS SOBRE A RECREAÇÃO: UM SABER DISCIPLINARIZADO NA ESCOLA DE EDUCAÇÃO FÍSICA DE MINAS GERAIS (1963 - 1969)}

\author{
DISCOURSES ABOUT RECREATION: KNOWLEDGE AS DISCIPLINES AT THE \\ MINAS GERAIS SCHOOL OF PHYSICAL EDUCATION (1963-1969)
}
DISCURSOS SOBRE LA RECREACION: UN SABER DISCIPLINARIZADO EN LA ESCUELA DE EDUCACIÓN FÍSICA DE MINAS GERAIS (1963 - 1969)

Hilton Fabiano Boaventura Serejo*, Hélder Ferreira Isayama**
Palavras chave:

Recreação.

Educação Física

e Treinamento.

Currículo

\begin{abstract}
Resumo: O objetivo deste texto foi compreender os discursos disciplinares relacionados à recreação na Escola de Educação Física de Minas Gerais (EEFMG), no período de 1963 a 1969. A apreciação dos dados encontrados se deu inspirada na análise de discurso sob a perspectiva arqueológica de Foucault e em diálogos com a história das disciplinas. Analisando os discursos, observamos que os significados sobre a recreação foram demarcados pelos enunciados "interesse" e "prazer". Foi evidenciada uma perspectiva dual da recreação, expressa na temática arma de dois gumes e recreação espontânea ou viciosa, que categoriza as ações em certas ou erradas, boas ou más, o que tornava secundários outros elementos presentes nessas vivências, como: solidariedade, cooperação e cidadania.
\end{abstract}

Keywords:

Recreation. Physical Education and Training. Curriculum.

\begin{abstract}
The purpose of this text was to understand the discourses related to recreation at disciplines of Minas Gerais School of Physical Education (EEFMG) from 1963 to 1969. Data were subjected to analysis of discourse under the archaeological perspective of Foucault and in communication with the history of the disciplines. Analyzing the discourses, we found that meanings of recreation were demarcated by interest and pleasure enunciations. We found a dual perspective on recreation, expressed in the twoedged weapon and spontaneous or vicious recreation, which categorizes actions as right or wrong, good or bad, making other elements present in these experiences secondary, such as solidarity, cooperation and citizenship.
\end{abstract}

Resumen: El objetivo de este texto fue comprender los discursos disciplinarios relacionados a la recreación en la Escuela de Educación Física de Minas Gerais (EEFMG), en el período de 1963 a 1969. La apreciación de los datos encontrados se dio inspirada en el análisis de discurso bajo la perspectiva arqueológica de Foucault y en diálogos con la historia de las disciplinas. Analizando los discursos, observamos que los significados sobre la recreación fueron demarcados por los enunciados interés y placer. Se evidenció una perspectiva dual de la recreación, expresada en la temática arma de doble filo y recreación espontánea o viciosa, que categoriza las acciones en correctas o equivocadas, buenas o malas, lo que volvía secundarios otros elementos presentes en esas vivencias, como: solidaridad, cooperación y ciudadanía.
*Universidade Federal dos Vales do Jequitinhonha e Mucuri. Diamantina, $M G$, Brasil.

E-mail: hiltonserejo@uol.com.br

**Universidade Federal de Minas Gerais (UFMG). Belo Horizonte, MG, Brasil. E-mail: helderisayama@yahoo.com.br

Recebido em: 26-10-2017 Aprovado em: 19-03-2019 Publicado em: 30-04-2019

DOI https://doi.org/10.22456/1982-8918.77663 (c) (1) (8) Licence 


\section{INTRODUÇÃO}

O objetivo deste texto foi analisar os discursos sobre recreação veiculados na primeira disciplina específica sobre essa temática a constar no currículo formal de um curso superior em EF da Escola de Educação Física de Minas Gerais (EEFMG), no período de 1963 a 1969. Para realizar este trabalho, inspiramo-nos na perspectiva arqueológica de Michel Foucault, nos aportes metodológicos da História, além dos diálogos com a História das Disciplinas.

Com relação às fontes históricas, utilizamos, principalmente, os documentos relacionados ao currículo prescrito, que se materializou nos documentos da época, com todas as suas variáveis. $O$ trabalho foi realizado por meio da pesquisa e análise documental. Ao priorizarmos as análises desse material, entendemos que as prescrições são emanadas não somente dos órgãos políticos e administrativos, mas também dos textos, manuais, programas e programações do professor (VIÑAO, 2007). Portanto, compreendemos que os discursos presentes nas disciplinas se iniciam com os documentos oficiais, por conseguinte, as primeiras documentações pesquisadas foram os textos oficiais programáticos, como ementas, programas, circulares, normas e leis. Para mobilizar as fontes desta pesquisa, acessamos 0 Centro de Memória da Educação Física, do Esporte e do Lazer (CEMEF), vinculado à Escola de Educação Física, Fisioterapia e Terapia Ocupacional (EEFFTO) da Universidade Federal de Minas Gerais (UFMG).

A EEFMG tem suas raízes em 1952, pela união de duas outras Escolas de Educação Física. Uma era ligada ao Estado de Minas Gerais, fundada pelo governo de Juscelino Kubitschek (JK); a outra pertencia às Faculdades Católicas, Sociedade Mineira de Cultura, presidida por D. Cabral, Arcebispo da Capital. Porém, em 1953 essas escolas se fundiram, dando origem à EEFMG, pois havia problemas financeiros para a manutenção dos cursos, além da baixa procura de candidatos pelos processos seletivos de ingresso (SOUSA, 1994).

Quanto à demarcação temporal, ela foi delimitada a partir do surgimento na matriz curricular da EEFMG da primeira disciplina específica sobre a recreação, em 1963, até 0 momento da federalização dessa instituição, que foi incorporada à Universidade Federal de Minas Gerais, em 1969.

Esclarecemos que as análises discursivas arqueológicas, baseadas em Foucault, evidenciam o que está explícito, o que está dito, logo, não analisam as intencionalidades que possam permear os documentos, mas os efeitos desses discursos na formação dos sujeitos. Nessa perspectiva, as histórias arqueológicas são móveis, pois se deslocam pelos discursos e pelas práticas, contornam os saberes e procuram descrever e individualizar os enunciados discursivos (FOUCAULT, 2008).

\section{A EEFMG E A DISCIPLINARIZAÇÃO DE UM SABER}

Para pensar na atuação profissional em EF que seria desejada para o período, ligada aos campos da recreação, consideramos necessário compreender como ocorreu 0 processo formativo nesse campo. Assim, perguntamo-nos: a recreação, considerada, então, uma disciplina, teria um papel relevante nesse processo de uma educação moralizadora e conformadora que se esperava da atuação dos profissionais de EF? Quais discursos foram manifestos nesse processo de disciplinarização? 
Ao pensarmos a recreação como uma cadeira acadêmica adotada na formação superior em EF, compreendemos que é necessário discutir quais as implicações que esse ordenamento disciplinar produz. Assim, Veiga-Neto (1996, p.298) explica que "as disciplinas especificam 0 que estudar e como relacionar entre si as coisas que estudamos; em outras palavras, elas nos fornecem critérios e métodos para ver e organizar objetos". Então, as disciplinas têm como efeito lançar luz sobre determinados objetos e procurar articulá-los segundo determinadas lógicas. Dessa forma, elas acabam por constituir o que Foucault denomina regimes de verdade.

Num primeiro momento, apresentamos questões gerais relacionadas à EEFMG e aos discursos oriundos das fontes que contextualizam esse processo. Assim sendo, o Regimento da EEFMG (CEMEF, 1968d), em seu Art. $2^{\circ}$, especificava que, entre os objetivos da escola, estava formar pessoal técnico em ginástica, recreação e desportos. Eram ofertados quatro cursos na instituição, a saber: o Superior de Educação Física, que se destinava a formar professores para atuar nas escolas de Educação Física; o de Educação Física Infantil, destinado à especialização de professores do ensino primário para o magistério da Educação Física Infantil; o de Técnica Desportiva, que visava formar técnicos em desportos; e, por fim, 0 de Medicina Aplicada à Educação Física, que especializava médicos para atuar em Educação Física e Desportos.

Com relação aos currículos e programas da EEFMG, constava no Regimento da EEFMG (CEMEF, 1968d, p. 5) que esses eram considerados como uma "ordenação das disciplinas a serem lecionadas em cada curso, através de aulas teóricas e práticas, seminários, trabalhos de pesquisa e quaisquer outras atividades aconselhadas pela natureza dos temas".

Ao abordar a questão de um saber alocado em uma cadeira, Veiga-Neto (1996) esclarece que Foucault considerava a disciplina-saber como unidades nas quais os saberes se agrupariam, dividiriam e articulariam entre si. Essa disciplina-saber estaria envolvida em um disciplinamento de condutas, em uma disciplina-corpo. Dessa forma, uma disciplina seria um campo de estudos e também uma forma de controle, o que reforça a ideia de que todo currículo está permeado por relações de saber e poder.

As matérias que comporiam os cursos da EEFMG eram distribuídas pelos diversos departamentos ${ }^{1}$ da Escola. A cadeira Recreação estaria sob a coordenação do Departamento Psicopedagógico². As disciplinas eram vistas como "uma unidade didática de uma matéria ou um programa de estudo e trabalho oferecido por um Departamento na sua área de cultura" (CEMEF, 1968d, p.7). Dessa forma, percebemos que os discursos emanados das disciplinas na EEFMG eram associados ao eixo cognitivo disciplina-saber. Contudo, todo saber visa formar alguém para um determinado mundo, assim a disciplina-saber é indissociável da relação com a disciplina-corpo.

Em relação ao período que antecedeu a implementação da disciplina Recreação, referimo-nos aos anos de 1960 a 1962, o diretor da EEFMG à época, Gen. Olavo Amaro da Silveira, encaminhou ao Presidente do Conselho Federal de Educação uma carta propondo mudança curricular (CEMEF, 1962c). Fruto de estudos do Conselho Técnico Administrativo (CTA), essa proposta foi aprovada pela Congregação da escola, que introduziu algumas

\footnotetext{
1 Conforme consta no Regimento da EEFMG, as disciplinas que compunham os cursos na Escola estavam ligadas a um dos cinco departamentos citados a seguir: Departamento Psicopedagógico, Departamento de Biologia, Departamento de Cinesioterapia, Departamento Gymno-rítmico e Departamento de Atividades Desportivas.

20 Departamento Psicopedagógico era composto pelas seguintes disciplinas: Organização e Administração da Educação Física e dos Desportos; Pedagogia Aplicada; Psicologia Aplicada; Antropologia; Recreação. Regimento da EEFMG, 1967 e 1968.
} 
mudanças no currículo. Uma delas dizia respeito aos cursos ofertados pela escola: Superior de Educação Física; Educação Física Infantil; Técnica Desportiva; Massagem; Medicina Aplicada à Educação Física e aos Desportos. O CTA e a Congregação sentiram necessidade de mudar essa estrutura e propuseram as seguintes alterações:

\section{Curso de Graduação:}

- Curso Superior de Educação Física (em 3 anos e destinado aos portadores de certificado de conclusão do curso de grau médio completo). [...]

Curso de Especialização: [...]

- Curso de Educação Física Infantil (em 1 ano letivo e destinado aos portadores de diploma de conclusão do curso normal).

- Curso de Recreação (em 1 ano letivo e destinado aos professores de Educação Física, aos professores do ensino médio, aos professores do ensino primário, aos assistentes sociais e aos orientadores sociais (CEMEF, 1962c, p. 6).

Outra mudança foi proposta na constituição dos currículos plenos, nos quais, no curso Superior de Educação Física, a disciplina Recreação seria ministrada no terceiro ano. Já na Educação Física Infantil haveria duas cadeiras sobre o assunto, uma no primeiro período letivo e outra no segundo. Mas, e no curso de especialização em Recreação, quais seriam as matérias lecionadas? Esse curso seria composto pelas seguintes disciplinas: Pedagogia Aplicada; Psicologia Aplicada; Técnica de Recreação; Organização e Administração da Recreação; Ginástica Geral; Atividades Recreativas e Cultura Religiosa. Ao final de um ano de curso, o aluno receberia o diploma de Técnico em Recreação. Todavia, não encontramos evidências empíricas da ocorrência dessa especialização em Recreação. A nosso ver, foi uma proposta que não se materializou, pois os discursos sobre esse curso desapareceram das estruturas curriculares da escola nos anos seguintes. Inclusive, não localizamos enunciados que elucidassem os motivos de sua não ocorrência.

Reiteramos que o Parecer no 298 da Comissão de Ensino Superior incorporou oficialmente a cadeira Recreação ao currículo mínimo dos cursos das escolas de Educação Física no Brasil. Assim, efetivamente, com essas mudanças, a Recreação, como uma disciplina, apareceria na matriz curricular do curso Superior de EF no terceiro ano do curso, nesse caso em 1965. No curso de EF Infantil, essa surgiria como disciplina em 1963. Essas mudanças curriculares estavam presentes em vários enunciados. Por exemplo, consta na ata da reunião ordinária da Congregação da EEFMG (CEMEF, 1962a), realizada no dia 28 de maio de 1962, que era necessária uma reforma curricular para tornar o ensino mais objetivo e atualizado para a época, bem como assegurar a flexibilidade e o inter-relacionamento das matérias que comporiam o currículo. Também, a ata da reunião extraordinária do Conselho Técnico Administrativo (CTA), do dia 26 de dezembro de 1962, registra que o curso de EF Infantil mostrava uma deficiência na formação proposta aos alunos, sendo necessário criar as cadeiras de Danças e Recreação (CEMEF, 1962b).

Segundo Sousa (1994), com a reorganização curricular do curso de EF da época, foram inseridas três disciplinas, a saber: Recreação, Dança e Pedagogia. Surge, então, uma questão inicial: quem seriam os docentes dessas cadeiras que surgiram nessa matriz curricular? Assim, entre essas disciplinas propostas, focaremos na de Recreação para compreender os discursos que eram divulgados nos documentos e identificar os docentes protagonistas nesse processo. Nesse sentido, consta na ata da reunião ordinária da Congregação da EEFMG, realizada em 18 de fevereiro de 1963, que: 
[...] o professor Geraldo Pinto de Souza sugere o preenchimento das cadeiras de Recreação e Pedagogia, com o conseguinte aproveitamento nas referidas cadeiras de Metodologia da Educação Física e Metodologia do Treinamento Desportivo, tendo a proposição merecido integral aprovação por parte da Congregação (CEMEF, 1963a, p. 2).

A Congregação da EEFMG apreciou essa questão e, em reunião realizada em 28 de fevereiro de 1963, indicou o professor de Metodologia do Treinamento Desportivo, Geraldo Pinto de Souza, para assumir a função de professor catedrático na cadeira de Recreação (CEMEF, 1963a). Dessa forma, o professor Geraldo Pinto de Souza teve papel protagonista nessa disciplina, como revelam as enunciações presentes nas fontes pesquisadas. Lembrando Foucault (2008), assim como o discurso dos médicos ganhava legitimação de autoridade e de verdade ao analisar questões na área da saúde, nos séculos XVIII e XIX, compreendemos que o status de professor catedrático na disciplina Recreação reforçaria critérios de competência e de saber observados nos discursos proferidos pelo referido docente. Isso, sobretudo, em se tratando de uma instituição educacional, nesse caso a EEFMG, o espaço legítimo de aplicação e origem dos discursos.

Ao ser indicado para ministrar a disciplina Recreação na EEFMG, o professor Geraldo Pinto de Souza encaminhou uma carta/ofício ao diretor e ao Conselho Técnico Administrativo (CTA) dessa instituição, em maio de 1963, solicitando que o professor Odilon Ferraz Barbosa assumisse, conjuntamente, essa cadeira na função de professor assistente, argumentando:

[...] que a Recreação, em sua estruturação quer teórica, quer prática, abrange assuntos de natureza recreativa os mais diversos; que em consequência da diversidade de assuntos, necessário se torna a presença de mais de um professor; que o professor Odilon Barbosa, em caráter extraordinário, há cerca de dois anos, vem ministrando aulas de recreação aos alunos dos Cursos Superior e Infantil; que o mencionado professor é portador de indiscutível aptidão e conhecimentos para o exercício das funções de professor recreacionista, no tocante aos assuntos relacionados à Educação Física (CEMEF, 1966b, p. 1).

A indicação do professor Odilon Ferraz Barbosa foi aprovada por unanimidade pelo Conselho Técnico Administrativo (CTA) na reunião do dia 15 de maio de 1963 e confirmada na reunião do CTA do dia 31 de maio de 1963 (CEMEF, 1966b). Desse modo, ele assumiu a função de professor assistente a partir de maio de 1963. Quanto ao professor Odilon Ferraz Barbosa, conhecido como Barbosinha, formou-se na EEFMG, em suas primeiras turmas. Foi docente nessa instituição até 1988, quando faleceu. Lecionou a disciplina Recreação e também Futebol de Salão (Futsal). Entretanto, foi na cadeira de Recreação que esse docente teve projeção nacional e internacional. Um exemplo dessa projeção se manifestou na $V$ Jornada Internacional de Educação Física, ocorrida em 1962 na EEFMG, na qual proferiu palestra sobre a recreação, tema abordado somente por professores de outros países antes da edição desse evento (CEMEF, 2015). Mas quais seriam os saberes desenvolvidos na cadeira de Recreação e como eram abordados á época? Questões para pensarmos a seguir.

\section{A DISCIPLINA RECREAÇÃO}

As disciplinas trabalham com saberes, mas não todo saber e sim um saber que é específico, circunscrito e considerado verdadeiro para a época (VEIGA-NETO, 1996). Dessa forma, é a disciplina que constitui a limitação dos conhecimentos trabalhados e essa 
circunscrição está permeada pelos objetivos, conteúdos e finalidades da disciplina. Assim, um ponto inicial, ao analisar uma disciplina, é procurar compreender quais são os seus objetivos.

Com relação aos objetivos da disciplina Recreação $0^{3}$, constatamos diferenças entre os que constavam no curso Superior de EF e os do curso de EF Infantil. Respectivamente, o curso Superior almejava "Indicar meios e processos construtivos de como analisar, discutir e discernir sobre determinado tema recreativo" e, para isso, deveria "Despertar no aluno o senso educativo da recreação em qualquer situação de vivência coletiva do homem" (CEMEF, 1968a, p. 1). Já o curso Infantil objetivava "Alertar as alunas sobre a importância atual da recreação em qualquer situação de vida em que se encontre o ser humano" e pretendia "Focalizar o valor da recreação, especificamente, na rua, na escola e no lar" (CEMEF, 1968a, p. 1).

Apesar de os programas, diários de classe e lista de pontos de prova serem similares nesses cursos, verificamos que os objetivos associados ao curso Infantil eram mais instrumentais em relação aos do curso Superior. Inclusive, há enunciações que reforçam essa premissa, ou seja, o curso Infantil deveria "ser estruturado, fundamentalmente, na recreação" (CEMEF, 1967b, p. 1). Os efeitos dessa instrumentalização materializavam-se no curso de Educação Física Infantil, que incluía como um de seus objetivos "treinar as professoras normalistas no magistério da Ed. Física". O termo "treinar" deixa tácito o caráter instrumental do curso, que procurava tornar as professoras "aptas, como recreacionistas, a organizar e dirigir sessões de recreação física orientada destinadas aos alunos das escolas pré-primária e primária” (CEMEF, 1969c, p. 1).

Conforme apontado, a disciplina Recreação foi inserida na matriz curricular da EEFMG em 1963. Nos documentos referentes a essa cadeira, no período de 1963 a 1969 (CEMEF, 1969e), uma abordagem prática foi predominante. Como exemplo disso, havia uma vasta relação de jogos e brincadeiras que deveriam ser desenvolvidas em um semestre letivo na disciplina. As fontes relacionadas aos conteúdos ministrados na disciplina Recreação evidenciaram que esse aspecto predominantemente prático se manteve na EEFMG até 1969 (CEMEF, 1969e), quando a instituição foi federalizada. Havia, inclusive, uma prova prática como uma das formas de avaliação previstas (CEMEF, 1963c). Portanto, a recreação, como um saber na formação em EF, esteve associada à ideia de aprendizagem de um rol de jogos e brincadeiras diversos.

Ainda segundo essas fontes, o professor Odilon Ferraz Barbosa seria o responsável pela parte prática da disciplina, enquanto o professor Geraldo Pinto de Souza se responsabilizaria pela parte teórica (CEMEF, 1969a). Essas enunciações, parte prática e parte teórica, constavam nos programas de ensino da disciplina Recreação. Refletindo sobre essa questão, compreendemos que tanto a teoria quanto a prática são partes de uma ação social humana, e isso não resulta que a teoria possa ser colocada em prática e nem que a prática almeje se tornar uma teoria. $\mathrm{O}$ que ocorre é a inter-relação dinâmica na qual uma tensiona a outra e se integram. Assim, essa integração acaba por influenciar a visão de mundo dos envolvidos e os efeitos disso reverberam no currículo, na formação profissional, na docência e em qualquer área de atuação (SANTOS FILHO, 1995).

Outros trabalhos que pesquisaram aspectos ligados à história da recreação e do lazer também mostraram uma dissociação entre teoria e prática, como os de Gomes (2003) e Brêtas (2007). Esses estudos apontaram que a atuação profissional nessas áreas era demarcada por seus aspectos prescritivos, pelo conhecimento de um vasto repertório de atividades e pelo

3 Somente a partir de 1967 é que encontramos explícitos, nos documentos, os objetivos da disciplina Recreação. 
domínio das questões operacionais em seus feitios técnico-metodológicos. De fato, a análise dos programas e planos de ensino da disciplina Recreação da EEFMG reflete essa visão dissociativa da relação teoria e prática. Afinal, como registram vários documentos, as aulas teóricas estariam sob a responsabilidade do professor Geraldo Pinto de Souza, enquanto as aulas práticas seriam ministradas pelo professor Odilon Ferraz Barbosa.

Com relação às questões teóricas, retomamos o primeiro programa da disciplina Recreação ofertada em 1963, no qual consta que seria discutido o seguinte: "Conceito de recreação e análise das expressões (orientada, espontânea, ativa, passiva, individual e coletiva)", o papel da recreação como arma de dois gumes e reflexões sobre "Conceito de prazer e sua evolução através dos tempos", "O que é recreação? Análise dos vocábulos - Re + Criar - Ação" e que os fins dessa temática estariam associados ao entretenimento, com objetivos "terapêutico, político - filosófico" (CEMEF, 1963c, p. 1). Alguns desses saberes marcaram a recreação nesse período e foram aspectos reiteradamente presentes nos conteúdos desenvolvidos à época, a saber: a questão da visão dessa área como uma arma de dois gumes; as enunciações "interesse" e "prazer" associadas à concepção de recreação; a ideia de recreação ativa, passiva, orientada, espontânea, individual e coletiva.

Quanto à questão da recreação como arma de dois gumes, tratada como uma questão dual, ela serviria tanto ao bem quanto ao mal. Esse aspecto esteve presente nos programas da disciplina Recreação no período de 1963 a 1969 e também em pontos de avaliação formal (CEMEF, 1969b). Exemplificando, um dos pontos de prova da disciplina Recreação, em 1963, era explicar o "Significado da expressão 'arma de dois gumes na recreação"' (CEMEF, 1963d, p. 1). E nos pontos para a prova de 1966 havia o seguinte enunciado "Qual o sentido educativo da expressão: 'arma de dois gumes?'” (CEMEF, 1966c, p. 1).

Nessa visão, as atividades recreativas não têm um fim em si mesmas, mas servem como uma arma contra os vícios, uma forma de reforçar uma perspectiva dualista, que categoriza as ações em certas ou erradas, boas ou más, o que torna secundários outros elementos presentes nessas vivências, como: prazer, solidariedade, cooperação e cidadania (BRÊTAS, 2007). Assim, compreendemos que os efeitos dessa abordagem estimulavam a manutenção de valores considerados socialmente válidos, que objetivavam a "paz social" - entendida como ausência de conflitos, mesmo que de forma dissimulada. Além disso, percebemos aproximações com as discussões que Marcellino (1987) produziu relacionadas às visões Funcionalistas de Lazer $^{4}$, todavia, durante o período analisado nesta pesquisa (1963 a 1969), essas análises ainda não haviam se concretizado no campo do lazer e da recreação.

Contudo, aos poucos, os documentos foram revelando o uso do termo "instrumento" no lugar de "arma" e, assim, a enunciação "instrumento de dois gumes" passou a aparecer nas fontes conjuntamente com "arma de dois gumes". Na cadeira Recreação foi recorrente encontrar essa enunciação, instrumento de dois gumes, bem como nos programas da disciplina Recreação ou nos pontos para as provas, tanto do curso Superior de EF, quanto do curso Infantil. A associação da recreação como instrumento de dois gumes agregada à ideia de recreação espontânea e recreação viciosa também estava presente nos documentos da época, da mesma forma que ocorreu com a enunciação arma de dois gumes (CEMEF, 1968c).

Concluindo essa questão, consideramos que os efeitos das enunciações ligadas ao vocábulo "arma" denotavam a ideia de um mecanismo bélico, militar, preparado ou adaptado

4 Optamos por não aprofundar as discussões ligadas a essa temática para não corrermos o risco de cometer um anacronismo. 
para prejudicar ou favorecer alguém ou algo. Com a mudança do termo para "instrumento", interpretamos que a recreação passou a ser um recurso utilizado para atingir um resultado, um meio capaz de ter implicações em diversas áreas da atividade humana. Apesar da reincidência das expressões "instrumento" ou "arma", outras enunciações também se fariam presentes para compreender a concepção de recreação à época. Referimo-nos aos vocábulos "interesse" e "prazer", abordados a seguir.

\section{ENUNCIAÇÕES SOBRE AS CONCEPÇÕES DE RECREAÇÃO}

Outra questão explícita se referia à associação da concepção de recreação aos vocábulos "interesse" e "prazer". Essas expressões estavam presentes em pontos das provas finais da disciplina Educação Física Geral, em 1960, antes da criação da disciplina Recreação, e passaram a constar dos programas e provas dessa cadeira no curso Superior de EF e no curso de EF Infantil da EEFMG (CEMEF, 1960).

A presença dessas enunciações nas provas refletiam os conteúdos que seriam desenvolvidos na disciplina Recreação, conforme atestam os programas e diários de classe da época: "Propriedades de recreação - interesse - Esquema prazer e dor"; "Esquema filosófico do prazer e dor"; "Diferenças entre interesse e prazer"; "Propriedades da Recreação: - Estudo analítico do prazer"; "Estudo analítico do interesse"; "Conceito de recreação como relação de conveniência recíproca entre a motivação do prazer e o interesse"; "Comparação do prazer como bem e da dor como mal"; "Relações comparativas entre prazer e interesse"; "Conceituação filosófica da relação: prazer e dor"; "O dilema prazer e interesse"; "Propriedades da Recreação - o interesse como fim da recreação"; "Propriedades da recreação - o prazer como meio da recreação" (CEMEF, 1969e, p. 1).

Essa correlação entre os enunciados presentes nas provas e os programas e diários de classe da disciplina Recreação no curso Superior de EF e no curso de EF Infantil evidencia que a concepção de recreação presente até 1969 foi demarcada pelas enunciações "interesse" e "prazer". Reforçando essa ideia, explicitam esses documentos que "Recreação é tudo aquilo que o ser vivo animal realiza com prazer" (CEMEF, 1969e, p. 2). Complementando essa enunciação, consta também que "recreação é tudo aquilo que o homem realiza com prazer, cujo resultado Ihe ofereça um sentido positivo de valorização". Observa-se aí a relação recíproca entre o prazer como um meio e o interesse biopsicossocial como um fim a ser alcançado. Dessa forma, se o prazer era o meio utilizado para se alcançar determinado fim, nesse caso, o interesse, então, estaria reforçando a ideia da recreação como atividades desenvolvidas com o intuito de diversão, distração ou divertimento, para satisfazer os interesses dos sujeitos envolvidos nessas ações. Com isso, é possível compreender a prevalência das ações práticas e a concepção de recreação predominante nesse período.

As fontes demonstram, também, que outras concepções de recreação eram abordadas, pois foi recorrente encontrar nos documentos pesquisados a enunciação "Conceitos de recreação" (CEMEF, 1969e, p. 1), assim grafada no plural. Algumas vezes, essas concepções eram complementadas com expressões como: "Conceitos Etimológicos de recreação" (CEMEF, 1969e, p. 1), "Conceitos analíticos de Recreação" (CEMEF, 1969e, p. 1), "Conceitos de recreação referentes a visões de lazer" (CEMEF, 1966a, p. 1), "Conceitos de Recreação referentes a hora de lazer" (CEMEF, 1966d, p. 1), "Conceituação sociológica da recreação 
em face dos tipos humanos encontrados na sociedade" (CEMEF, 1967d, p. 1), "Conceito de Recreação como atividade física e mental” (CEMEF, 1967c, p. 1), entre outras.

Com relação à etimologia da palavra recreação, recomendava o programa da disciplina, em 1963, que, para se discutir a concepção de recreação, seria necessário analisar sua composição (Re + Criar + Ação) para o entendimento de seu significado (CEMEF, 1963e). Nesse sentido, a obra de Inezil Penna Marinho foi referência para o período. $O$ autor explica que a recreação "[...] provém do latim (recreatio, recreationem) e significa vulgarmente 0 mesmo que recreio (divertimento, entretenimento); deriva do vocábulo recreare, cujo sentido é o de reproduzir, restabelecer, recuperar (quem trabalha precisa renovar-se)" (MARINHO, 1971, p.134).

Compreendemos que a etimologia da palavra recreação está associada a duas posições distintas, ambas derivadas de recreare. Uma estaria associada à ideia de reprodução, recuperação das energias e restabelecimento da força de trabalho, e a outra à premissa de recriar, de criar de novo, de dar novos sentidos às práticas (GOMES, 2003; MARCELLINO et al., 2011). A primeira posição, que associa a ideia da recreação a uma visão utilitarista e pragmática, foi a que prevaleceu nas enunciações presentes nos documentos da EEFMG.

Ainda sobre as enunciações ligadas às concepções de recreação, ao procurarmos entender essa associação com o campo do lazer nas fontes pesquisadas, encontramos uma enunciação que ajudou a elucidar essa questão, qual seja: "Recreação é atividade livremente escolhida e exercida nas horas de lazer" (CEMEF, 1965, p. 1). Esse discurso da recreação como ocupação das horas de lazer, ou então como atividade física ou mental, tem como efeito reforçar a premissa de que recreação e lazer eram considerados como fenômenos distintos na EEFMG no período analisado.

Reforçam, ainda, essa premissa as seguintes questões presentes em pontos de prova da disciplina Recreação: "O que são horas de lazer? Como se enquadram no conteúdo da recreação?"; "Significado da expressão "horas de lazer"'; "Qual a importância da recreação nas horas de lazer?"; ou então "Pode haver recreação fora das horas de lazer?" (CEMEF, 1969e, p. 1). Assim, a recreação seria considerada como uma atividade, uma possibilidade de ocupação das horas de lazer. O lazer apareceu associado ao vocábulo "horas", o que evidencia que esse fenômeno seria compreendido como tempo liberado das obrigações. Dessa forma, seria o tempo o elemento essencial para a compreensão do lazer e a recreação torna-se uma das possibilidades de ocupação desse tempo.

Assim, nesse contexto, o significado de lazer estava associado ao tempo. A esse respeito, as pesquisas de Gomes (2003) e Brêtas (2007) demonstraram que essa associação era antiga e que o lazer corresponderia ao tempo do não trabalho, tempo de recreio, tempo de descanso, entre outras expressões. Além do mais, era considerado um mecanismo de controle social que valorizava a ocupação desse tempo com atividades recreativas consideradas úteis, saudáveis e produtivas. Mas, será que a recreação ocorreria apenas no tempo de lazer?

A resposta a esse questionamento encontra-se nas enunciações constantes nos programas e listas de pontos de provas da disciplina ofertada no curso Superior de EF e no curso de EF Infantil. Esse material explicita que haveria discussões dirigidas, debates, sobre as seguintes temáticas: "A recreação e o ser humano em uma longa viagem de avião"; "A recreação e o ser humano no velório de uma pessoa amiga"; "A recreação em uma diligência 
policial preventiva"; "A recreação em uma atividade de cunho religioso"; "A recreação no tratamento de uma saúde", "A recreação, o ser humano e a guerra"; "Recreação orientada: na rua, no lar, no hospital, na igreja, no quartel (situação de paz - situação de guerra), em viagem, no trabalho, na penitenciária" (CEMEF, 1968, p. 1).

Como a recreação se relacionava com atividades que divertiam, marcadas por interesse e prazer, essa ação poderia ocorrer a qualquer momento, inclusive concomitantemente às obrigações profissionais ou, até mesmo, em momentos de dor, tristeza, martírios, como o caso da guerra e do velório. Percebemos, então, um viés utilitário na recreação, vista não só com o sentido de divertir, mas também para recuperar as energias e voltar revigorado para outra ação. Inclusive, isso se manifestaria na visão da Educação Física. A esse respeito, em um dossiê sobre a prática da disciplina Educação Física em cursos noturnos, em 1967, cujo objetivo era demonstrar a relevância dessa área para a formação dos estudantes que teriam aulas à noite, entre os princípios básicos da área, destaca-se a questão do tempo livre. Nas enunciações presentes nesse dossiê, "A Educação Física e os Esportes preparam o homem para o seu papel na vida (trabalho e lazer)", com o intuito de aliviar as tensões do dia a dia. Reforça-se, assim, o seu papel utilitário.

Portanto, baseava-se que as ações desportivas e ginásticas deveriam ter consonância com os usos do tempo livre e cujas funções eram: "função de superação (êxito na prova), função de diversão (jogo) e função de descanso (relaxamento)" (CEMEF, 1967a, p. 1). Evidenciamos a relação dessas enunciações com os estudos de Dumazedier (1973), nos quais o lazer têm três funções bem definidas, a saber: o descanso; o divertimento; o desenvolvimento pessoal e social. Para o autor, essas funções são solidárias e se encontram presentes "[...] em todas as situações e em relação a todos os indivíduos; podem suceder-se ou coexistir-se; manifestarse uma de cada vez ou simultaneamente na mesma situação de lazer" (DUMAZEDIER, 1973, p.34).

Concluindo, as funções de diversão e descanso, relacionadas ao objetivo recreacional, incentivavam a "[...] importância de se ensinar atividades que possam ser levadas da escola para preencher o tempo livre que se faz cada vez mais amplo, na vida atual" (CEMEF, 1967a, p. 1). Portanto, buscava-se compreender que a recreação e o lazer contribuíam para 0 desenvolvimento pessoal e social dos indivíduos, apesar de uma perspectiva moralizante e utilitária que perpassaria os discursos, à época, sobre essas temáticas.

\section{CONSIDERAÇÕES FINAIS}

Procuramos analisar os discursos oficiais da recreação nos currículos do curso de EF da EEFMG, de 1963 a 1969. Para isso, analisamos o que esses discursos procuraram divulgar e legitimar em seus documentos. Portanto, tivemos que identificar as estratégias discursivas oriundas das fontes pesquisadas para compreender os significados difundidos sobre essas temáticas.

Concluímos que a recreação, como um saber, fez parte da formação profissional em EF em MG desde os seus primórdios. Com referência aos discursos relativos à recreação, eles foram demarcados por enunciações que os relacionavam a diversos aspectos, dentre eles: a recreação como arma de dois gumes, ou como instrumento de dois gumes. Ressaltamos, ainda, que a recreação se ligava às enunciações interesse e prazer, logo, a busca pela diversão 
caracterizava essa área. Daí a manifestação de uma abordagem técnica e metodológica de reprodução de atividades, com o fim de canalizar as tensões e amenizar os problemas sociais.

Por fim, nossa intenção não era e nem poderia ser esgotar a discussão sobre o assunto, tampouco apreender o que seria verdadeiro, ou mesmo tecer juízos de valor sobre as temáticas estudadas. Assim sendo, as análises que desenvolvemos podem ser reexaminadas, novas fontes podem ser pesquisadas e aparecerem outras interpretações. Desse modo, esperamos que este estudo possa contribuir para o avanço nas reflexões sobre os discursos que marcaram a constituição da recreação e do lazer como saberes presentes na formação em EF em MG. E, então, algumas lacunas nas discussões historiográficas, curriculares e, especialmente, ligadas à formação e atuação profissional em recreação e lazer poderão ser preenchidas.

\section{REFERÊNCIAS}

BRÊTAS, Angela. "Nem só de pão vive o homem": criação e funcionamento do Serviço de Recreação Operária (1943-1945). 2007. 367f. Tese (Doutorado em Educação) - Programa de Pós-Graduação em Educação, Universidade do Estado do Rio de Janeiro, Rio de Janeiro, 2007.

CEMEF. Centro de Memória da Educação Física, do Esporte e do Lazer da EEFFTO da UFMG. Ata da Congregação de 18 de fevereiro de 1963. Belo Horizonte, 1963a.

CEMEF. Centro de Memória da Educação Física, do Esporte e do Lazer da EEFFTO da UFMG. Ata da Congregação de 28 de maio de 1962. Belo Horizonte, 1962a.

CEMEF. Centro de Memória da Educação Física, do Esporte e do Lazer da EEFFTO da UFMG. Ata do CTA de 26 de dezembro de 1962. Belo Horizonte, 1962b.

CEMEF. Centro de Memória da Educação Física, do Esporte e do Lazer da EEFFTO da UFMG. Atas do CTA, 1963. Belo Horizonte, 1963b.

CEMEF. Centro de Memória da Educação Física, do Esporte e do Lazer da EEFFTO da UFMG. Diário de Classe Recreação. 1966. Belo Horizonte, 1966a.

CEMEF. Centro de Memória da Educação Física, do Esporte e do Lazer da EEFFTO da UFMG. Diários de Classe e Programas da Disciplina, 1963 a 1969. Belo Horizonte, 1969a.

CEMEF. Centro de Memória da Educação Física, do Esporte e do Lazer da EEFFTO da UFMG. Diversos do professor Geraldo Pinto de Souza, 1958-1966. Belo Horizonte, 1966b.

CEMEF.Centro de Memória da Educação Física, do Esporte e do Lazer da EEFFTO da UFMG. Diversos, 1963 a 1969. Belo Horizonte, 1969b.

CEMEF. Centro de Memória da Educação Física, do Esporte e do Lazer da EEFFTO da UFMG. Dossiê da EF em cursos noturnos, 1967. Belo Horizonte, 1967a.

CEMEF. Centro de Memória da Educação Física, do Esporte e do Lazer da EEFFTO da UFMG. Esboço do Curso de EF Infantil, 1969. Belo Horizonte, 1969c.

CEMEF. Centro de Memória da Educação Física, do Esporte e do Lazer da EEFFTO da UFMG. Lista de pontos para a prova, 1967. Belo Horizonte, 1967b. 
CEMEF. Centro de Memória da Educação Física, do Esporte e do Lazer da EEFFTO da UFMG. Matéria Lecionada Recreação, 1963. Belo Horizonte, 1963c.

CEMEF. Centro de Memória da Educação Física, do Esporte e do Lazer da EEFFTO da UFMG. Pontos para a prova parcial - Disciplina Educação Física Geral, 1960. Belo Horizonte, 1960.

CEMEF. Centro de Memória da Educação Física, do Esporte e do Lazer da EEFFTO da UFMG. Pontos para a prova, 1963. Belo Horizonte, 1963d.

CEMEF. Centro de Memória da Educação Física, do Esporte e do Lazer da EEFFTO da UFMG. Pontos para a prova. Belo Horizonte, 1966c.

CEMEF. Centro de Memória da Educação Física, do Esporte e do Lazer da EEFFTO da UFMG. Programa da disciplina Recreação, 1966. Belo Horizonte, 1966d.

CEMEF. Centro de Memória da Educação Física, do Esporte e do Lazer da EEFFTO da UFMG. Programa Recreação, 1965. Belo Horizonte, 1965.

CEMEF. Centro de Memória da Educação Física, do Esporte e do Lazer da EEFFTO da UFMG. Programas da disciplina Recreação, 1967 e 1968. Belo Horizonte, 1968a.

CEMEF. Centro de Memória da Educação Física, do Esporte e do Lazer da EEFFTO da UFMG. Programas diversos de Recreação, 1963 a 1969. Belo Horizonte, 1969d.

CEMEF. Centro de Memória da Educação Física, do Esporte e do Lazer da EEFFTO da UFMG. Programas e provas de Recreação, 1967 e 1968. Belo Horizonte, 1968b.

CEMEF. Centro de Memória da Educação Física, do Esporte e do Lazer da EEFFTO da UFMG. Programas e Provas Recreação, 1963 a 1969. Belo Horizonte, 1969e.

CEMEF. Centro de Memória da Educação Física, do Esporte e do Lazer da EEFFTO da UFMG. Programas Recreação, 1963. Belo Horizonte, 1963e.

CEMEF. Centro de Memória da Educação Física, do Esporte e do Lazer da EEFFTO da UFMG. Programas Recreação, 1967. Belo Horizonte, 1967c.

CEMEF. Centro de Memória da Educação Física, do Esporte e do Lazer da EEFFTO da UFMG. Proposta de mudança curricular, 1962. Belo Horizonte, 1962c.

CEMEF. Centro de Memória da Educação Física, do Esporte e do Lazer da EEFFTO da UFMG. Provas, 1967. Belo Horizonte, 1967d.

CEMEF. Centro de Memória da Educação Física, do Esporte e do Lazer da EEFFTO da UFMG. Regimento da EEFMG, 1967 e 1968. Belo Horizonte, 1968c.

DUMAZEDIER, Joffre. Lazer e cultura popular. São Paulo: Perspectiva, 1973.

FOUCAULT, Michel. A Arqueologia do Saber. 7. ed. Rio de Janeiro: Forense Universitária, 2008.

GOMES, Christianne Luce. Significados de recreação e lazer no Brasil: reflexões a partir de análises de experiências institucionais (1926 - 1964). 2003. 322f. Tese (Doutorado em Educação) - Programa de Pós-Graduação em Educação, Universidade Federal de Minas Gerais, Belo Horizonte, 2003. 
MARCELLINO, Nelson Carvalho. Lazer e Educação. Campinas, SP: Papirus, 1987.

MARCELLINO, Nelson Carvalho et al. Importância da Recreação e do Lazer. In: MARCELLINO, Nelson Carvalho et al. (org.). Cadernos interativos: elementos para o desenvolvimento de políticas, programas e projetos intersetoriais, enfatizando a relação lazer, escola e processo educativo. Brasília: Gráfica e Editora Ideal, 2011. v. 4.

MARINHO, Inezil Penna. Educação Física, Recreação: Jogos. 2. ed. São Paulo: Cia Brasil Editora, 1971.

SANTOS FILHO, José Camilo dos. Teoria e Prática: a relação possível e necessária. Motrivivência, v. 7, n. 8, p.11-30, dez. 1995.

SOUSA, Eustáquia Salvadora de. Meninos, à marcha! Meninas, à sombra. A história do ensino da Educação Física em Belo Horizonte (1897-1994). 1994. 265f. Tese (Doutorado em Educação). Programa de Pós-Graduação em Educação da Universidade Estadual de Campinas: UNICAMP, 1994.

VEIGA-NETO, Alfredo José. A ordem das disciplinas. 1996. 344f. Tese (Doutorado em Educação) - Programa de Pós-Graduação em Educação, Universidade Federal do Rio Grande do Sul, Porto Alegre, 1996.

VIÑAO, Antonio. A história das disciplinas escolares. Revista Brasileira de História da Educação, n. 18, p. 172-215, set./dez.2007. 